BNL- -35985

DE85 009824

\title{
NSLS INFRA-RED BEAM LIAE (U3) CONCEPTUAL DESIGN REPORT
}

\author{
G.P. Williams
}

February 9.1984

\section{RESEARCH SUPPORTED BY THE \\ OFFICE OF BASIC ENERGY SCIENCES}

U.S. DEPARTMENT OF ENERGY

WASHIHGTON, D.C.

\section{NATIONAL SYMCHFOTRON LIGHT SOURCE BROOKHAVEN NATIONAL LABORATORY ASSOCIATED UNIVERSITIES, INC.}




\section{List of Contents}

Page

1. Introduction 2

2. Design Goals 2

3. I $-R$ Beam Extraction 2

4. Optical Design 3

5. Power Loading of First Mirror 4

6. Vibration 5

7. Diffraction 5

8. Platform Specifications 6

9. Vacuum Considerations 6

10. First Mirror Pair Removal 6

11. Focusing Mirrors 6

\section{DISCLAIMER}

This report was prepared as an account of work sponsored by an agency of the United States
Government. Neither the United States Government nor ans asengy thereof, nor any of their employees, makes any warranty, express or implied, nor any agency thereof, nor any of their bility for the accuracy, completeness, or uefulied, or assumes any legal liability or reaponaiprocess disclosed, or represents that its use would of any information, apperatus, product, or ence herein to any specific commercial product, process, or privately owned rights. Refermanufactures, or otherwise does not necessarily constitute service by trade name, trademark, mendation, or favoring by the United States Government or imply its endorsement, recomand opinions of authors expressed herein do not necesserily agency theroof. The views United States Government or any agency thereof. necessarily state or reflect those of the 


\section{Introduction}

We describe the conceptual design of an infrared (I-R) beam line on the vacuum-ultra-violet storage ring of the National Synchrotron Light Source. The beam line forms part of the Phase II expansion of the NSLS. Consistent with the implementation of the current design is the extraction of hitherto wasted radiation and the establishment of a mezzanine floor or platform to make full use of the available headroom. This means that the I-R beam line, once established, does not interfere with any existing operations on the VUV floor.

\section{Design Goals}

The primary design goal is to extract 90 mradians horizontally by 90 mradians vertically of radiation from the VUV ring and transport it to an accessible $1: 1$ focus with no complex angle reflections. It is assumed that there is a requirement to use radiation up to wavelengths of $1 \mathrm{~mm}$. The large acceptance angle is needed therefore to preserve the source brightness at long wavelengths where diffraction would play a significant role as well as to match the synchrotron radiation natural opening angle. (See Fig. 1 and Table I) An additional design goal is to have the ability to replace all the optics without breaking machine vacuum.

Current VuV beam lines are limited to a 10 mradian vertical angle by the geometry of the ring vacuum chamber and the location of the ports with respect to the dipole magnets. A substantial amount of design work is needed to establish a feasible concept for the $I-R$ beam line front end design which overcomes these limitations.

The absence of complex angle reflections, if possible, allows for control and understanding of the polarization properties of the beam. Nothing in the design rules out the use of radiation in the VUV down to $300 \mathrm{~A}$.

\section{I-R Beam Extraction}

The scheme selected for extracting a beam with a large opening angle is shown in Fig. 2. This is an artist's impression of the VUV dipole magnet coils with the electron beam vacuum chamber passing through it. Shown are the existing $5^{\circ}$ and $22^{\circ}$ ports and the suggested infra-red port at $33.5^{\circ}$. It can be seen that the extracted beam is of radiation which would otherwise be wasted. The front end design allows the primary restriction in vertical aperture (the dipole coil separation) to be much closer to the source and hence subtend a much larger angle. Furthermore a wide vertical slot of $40 \mathrm{~mm}$ would be cut in the ring vacuum chamber compared to the $6 \mathrm{~mm}$ at a standard port. The length of the slot would be $290 \mathrm{~mm}$ compared to $168 \mathrm{~mm}$ or $216 \mathrm{~mm}$ on a standard port. As far as the electron beam is concerned, thin film resistors 
are required on the side of the extraction line to compensate for the change in impedance which such an orifice represents. The design shown in Fig. 2 also calls for water cooling around the new front end wile preserving the existing cooling and for additional cooling at the back of the new chamber in case the first mirror is removed as will be discussed later.

\section{Optical Design}

The optical design is controlled by (a) high power loadings on the first mirror (b) the need to transport the beam out of and away from the ring without interference with existing ports (c) diffraction and (d) the desire only to have pure horizontal or pure vertical deflections of the beam for polaricacion control. Folding in all these factors we arrive at the conceptual design shown in Fig. 3.

The I-R beam is extracted by $M I$, which is a plane mirror $661 \mathrm{~mm}$ from the source and of dimensions $63 \times 90 \mathrm{~mm}$. MI will have to be cooled and may be made of silicon carbide. There is thus a clear advantage in having a simple figure. In addition since the mirror is relatively inaccessible it would be hard to design an in situ manipulator which would be necessary if Ml were a focusing mirror. $M 2$ is also a plane mirror of size $115 \times 163 \mathrm{~mm}, 550 \mathrm{~mm}$ above $M 1$ and the $M 1, M 2$ combination is designed to be able to be inserted (or extracted) as a prealigned pair without breaking machine vacuum (see later). The M1,M2 "periscope" sends the beam back along in the "upstream" direction of the electron beam to $M 3$, which is an ellipsoidal mirror $145 \mathrm{~mm} \times 205 \mathrm{~mm}$ situated $314 \mathrm{~mm}$ from M2. M3 deflects the beam horizontally by $90^{\circ}$ (p-polarization) onto the experimental floor where it is intercepted by plane mirror M4 $880 \mathrm{~mm}$ away and of dimension $72 \times 102 \mathrm{~mm}$. M4 deflects the beam vertically to $M 5$ which is $820 \mathrm{~mm}$ away and is a focusing mirror identical to M3. Thus, an image of the source with a magnification of 0.9 is produced (primary focus) between $M 4$ and $M 5$ which is remagnified to give a $1: 1$ image (secondary focus) near the window, $1550 \mathrm{~mm}$ from $M 5$.

The elevation of the secondary focus is 1.4 meters above the platform which is roughly 2.8 meters above the VUV floor. 1.4 meters is also the elevation of the VUV ring.

For the secondary focus, a number of beam line options are possible. one of which is to refocus onto the entrance slit of a grating spectrometer. Another depicted schematically in Fig. 3 is to collimate the beam into an interferometer. We envisage the possibility of at least two experimental stations on the platform at the same time using moveable defiecting mirrors to share the available beam. 


\section{Power Loading of First Mirror}

The first mirror will be situated $661 \mathrm{~mm}$ from the source and thus the power per unit of horizontal iength $D$

$$
P=14.09 E^{4} I \sin \alpha / D D
$$

where $E=$ electron beam energy in $\mathrm{GeV}, I=$ beam current in $\mathrm{mA}, \rho=$ dipole bending radius in meters, $D=$ source to mirror distance in $\mathrm{cm}, \alpha=$ angle of incidence (from S. Krinksy "Heat Transfer with a Split Water Channel" BNL 24297)

$$
\begin{aligned}
& =1409(.75)^{4} 1000.1 / 1.91 \times 65.6 \\
& =35.6 \mathrm{~W} / \mathrm{cm}
\end{aligned}
$$

Since the mirror is $6.3 \mathrm{~cm}$ wide, the total power

$$
=6.3 \times 35.6
$$

Thus: Total power on $M 1=224$ watts

If we assume the radiation vertical opening angle

$$
2 \sigma=.8 \text { mradians }
$$

Then the beam height at the mirror set at $45^{\circ}$

$$
\begin{aligned}
& =0.2 \sigma / \sin 45^{\circ} \\
& =.74 \mathrm{~mm}
\end{aligned}
$$

Thus: Power density on $M 1=35.6 / 0.74 \mathrm{~W} / \mathrm{cm}^{2}$

$$
=481 \text { watts } / \mathrm{cm}^{2}
$$

We can see, therefore, that we have a situation for $M 1$ in which the total power is rather modest and could easily be handled by good contact conventional water cooling as in our water cooled masks. The power density at the center, however, would require cooling approaching the state-of-the-art if it were applied to the whole mirror. A careful thermal distribution analysis needs to be performed, therefore, to decide on the correct strategy for cooling this mirror. Due to the long wavelengths to be reflected there is more tolerance of thermally induced figure changes. One alternative design is to "slot" the mirror so that the central. 8 mradians passes through. Fig. 1 shows that this would have minimal effect on the I-R collection efficiency but it would impose severe constraints on both the MI positioning and orbit reproducibility which are best avoided if possible. 


\section{Vibration}

There is a strong desire to minimize the effect of mirror vibration since some of the experiments involve measurements of changes of 1 part in $10^{4}$. We assume, however, that the existing floor satisfies our requirements and will design the mirror holders and the platform to match. Thus each mirror support will be connected to a rigid support frame which rests directly on the floor. In the case of $\mathrm{MI}$ and $\mathrm{M2}$, a bellows isolates any vibrations from the ring, and the mirror pair support structure is a serarate structure resting directly on the VUV concrete floor.

\section{Diffraction}

When radiation passes through an aperture, diffraction occurs whose magnitude is proportional to the wavelength and the size of the aperture. the opening angle $\Omega$ for light of wavelength $\lambda$ passing through an aperture of area $A$ is given approximately by

$$
\Omega=\frac{\lambda^{2}}{A}
$$

In the infrared the optical design criterion normally used is to satisfy

$$
\frac{A \Omega}{\lambda^{2}} \geq I
$$

for all sections of the beam transports for the longest wavelength to be used. In our case the longest wavelength considered is $1 \mathrm{~mm}$ and we have been almost able to satisfy this condition. Thus the mirrors are slightly larger than they would be in the absence of diffraction effects.

Consideration of diffraction effects also eliminated the concept of a "collimated beam" for long distance beam transport, and led to the design with primary and secondary foci. If M3 were a collimating mirror, for example, M4 would have to be much larger than $M 3$, depending on its distance away. Furthermore, since $M 3$ just fits a $10 " 0 . n$. contact flange, alternative designs of this "collimated beam" type would involve very large diameter pipes and flanges.

In practice a program has been written which calculates the diffraction pattern at M2 from MI etc. and on which the mirror sizes are based. 


\section{Platform Specifications}

We require the platform to support two $4^{\prime} \times 8^{\prime}$ optical benches and ancillary equipment. It must be supported using pillars located at the U1/U2 and U2/U3 boundary lines. In size it is approximately $20^{\prime} \times 25^{\prime}$ ' including stairs. As far as vibration is concerned the specifications are the same as for the VUV floor. The conceptual design is shown in Fig. 4.

\section{Vacuum Considerations}

Up to the secondary focus the beam line will be at ultra-high vacuum. There will be no window separating the beam line from the ring vacuum. In the first section there will be a $220 \mathrm{l} / \mathrm{sec}$ ion pump/TSP combination to cope with the expected high photodesorbed gas loads at and around $M I$. A gate vaive will be used to isolate the beam line but it can only be closed after retraction of the $M 1, M 2$ combination. Near the primary focus there will be an aperture, a fast valve and an automatic valve to protect the ring from downstream accidents.

\section{First Mirror Pair (M1/M2) Removal}

The M1/M2 conceptual design is shown in Fig. 5. A linear motion drive allows the support structure to be retracted through the gate valve and hence removed. The support structure and the top part of the vacuum vessel are held on their own support frame, vibration isolated from the ring chamber by a bellows. When the prealigned M1/M2 pair are inserted, linear feedthroughs at the side are used to dampen vibrations which may be amplified by the long support and drive structure. Water cooling is built into the back of the lower chamber to take the thermal loads present during mirror removal.

\section{Focusing Mirrors $M 3, M 5$}

M3 and M5 are identical ellipsoidal mirrors whose shape is shown on Fig. 6. Their size is $145 \mathrm{~mm} \times 205 \mathrm{~mm}$ and procurement requires special consideration. If they are to be diamond tuned metal mirrors, the turning machine must have a clear throat of $90.5^{\prime \prime}$. Ray tracing of a toroidal mirror was made but it turns out to give an inadequate focus at wavelengths shorter than 100 wn. 


\begin{tabular}{|ccc|}
\hline$\lambda(\mu \mathrm{N})$ & $\begin{array}{c}\text { Flux } \\
\text { Photons } / \mathrm{Sec} / 0.1 \% \Delta \lambda / \lambda\end{array}$ & $\begin{array}{c}\text { Radiation Opening } \\
\text { Angle (mrads) } \mathrm{VxH}\end{array}$ \\
\hline 1 & $5.8 \times 10^{14}$ & $9 \times 90$ \\
10 & $2.9 \times 10^{14}$ & $35 \times 90$ \\
100 & $1.2 \times 10^{-4}$ & $95 \times 90$ \\
1000 & $5.6 \times 10^{13}$ & $90 \times 90$ \\
& & \\
\hline
\end{tabular}

Table I. Characteristics of the NSLS Emission in the Infra-Red 

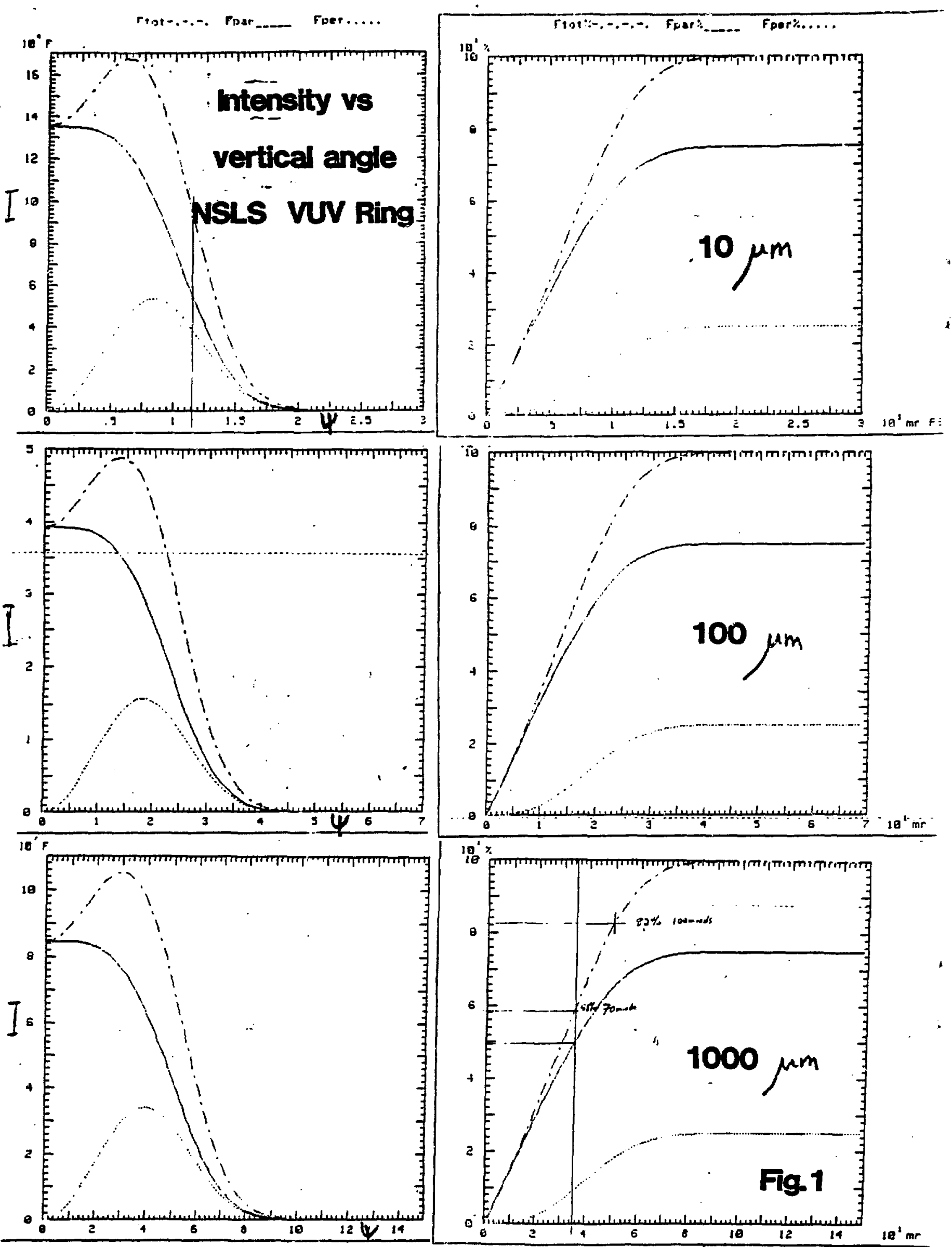


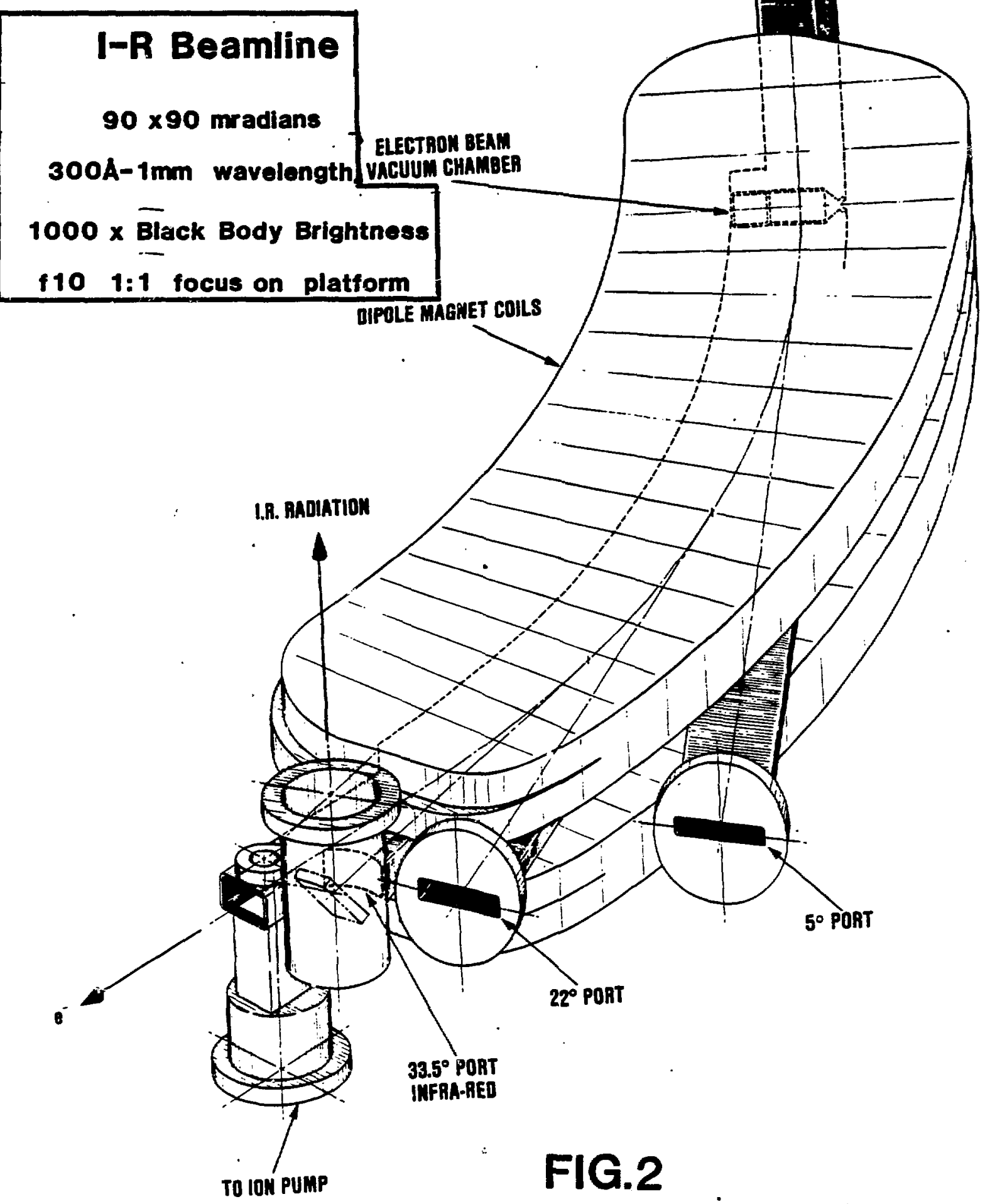

NSLS Phase2 Infra-Red Beam Extraction 


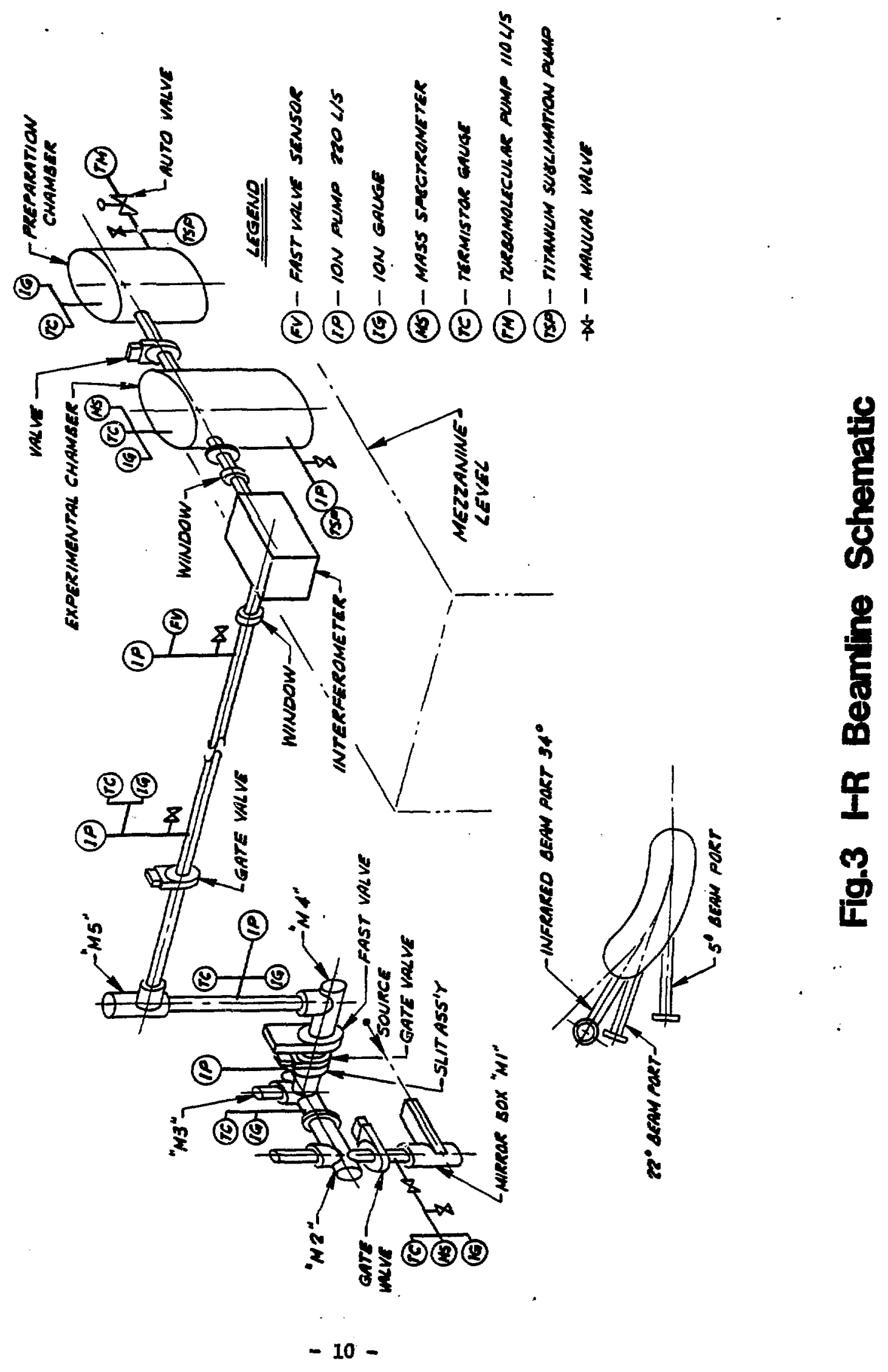




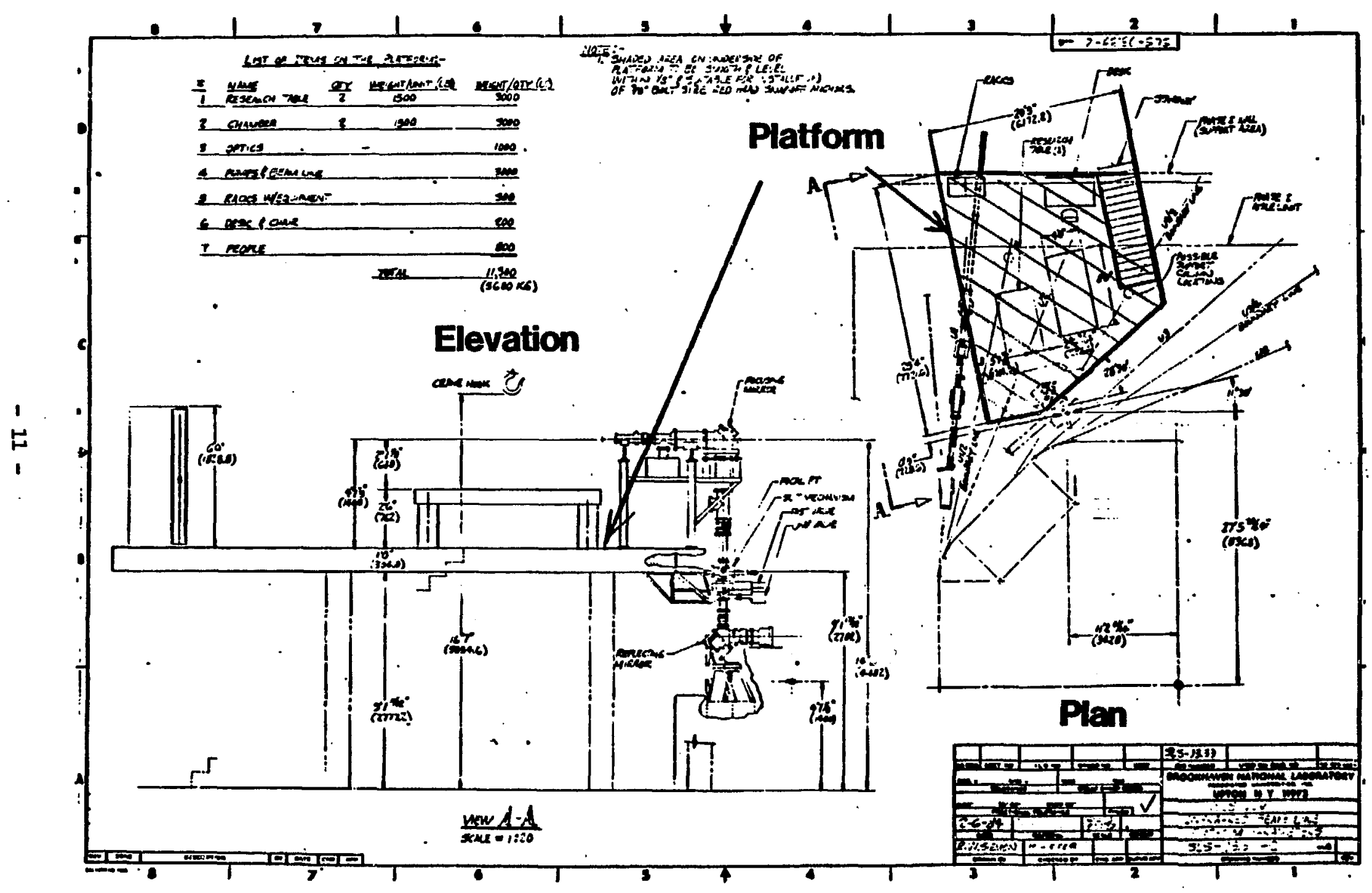

Fig.4 HR Beam Ine 


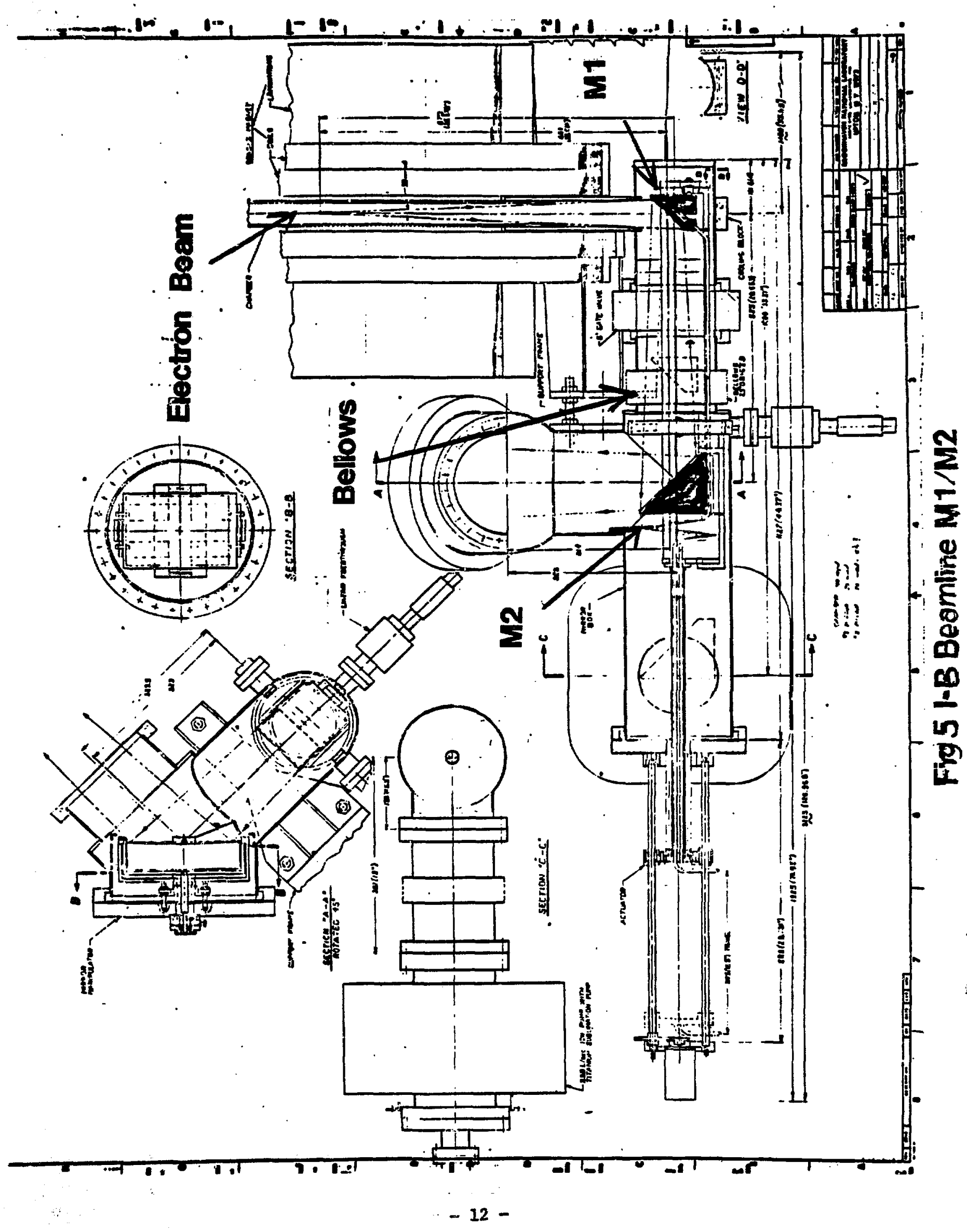




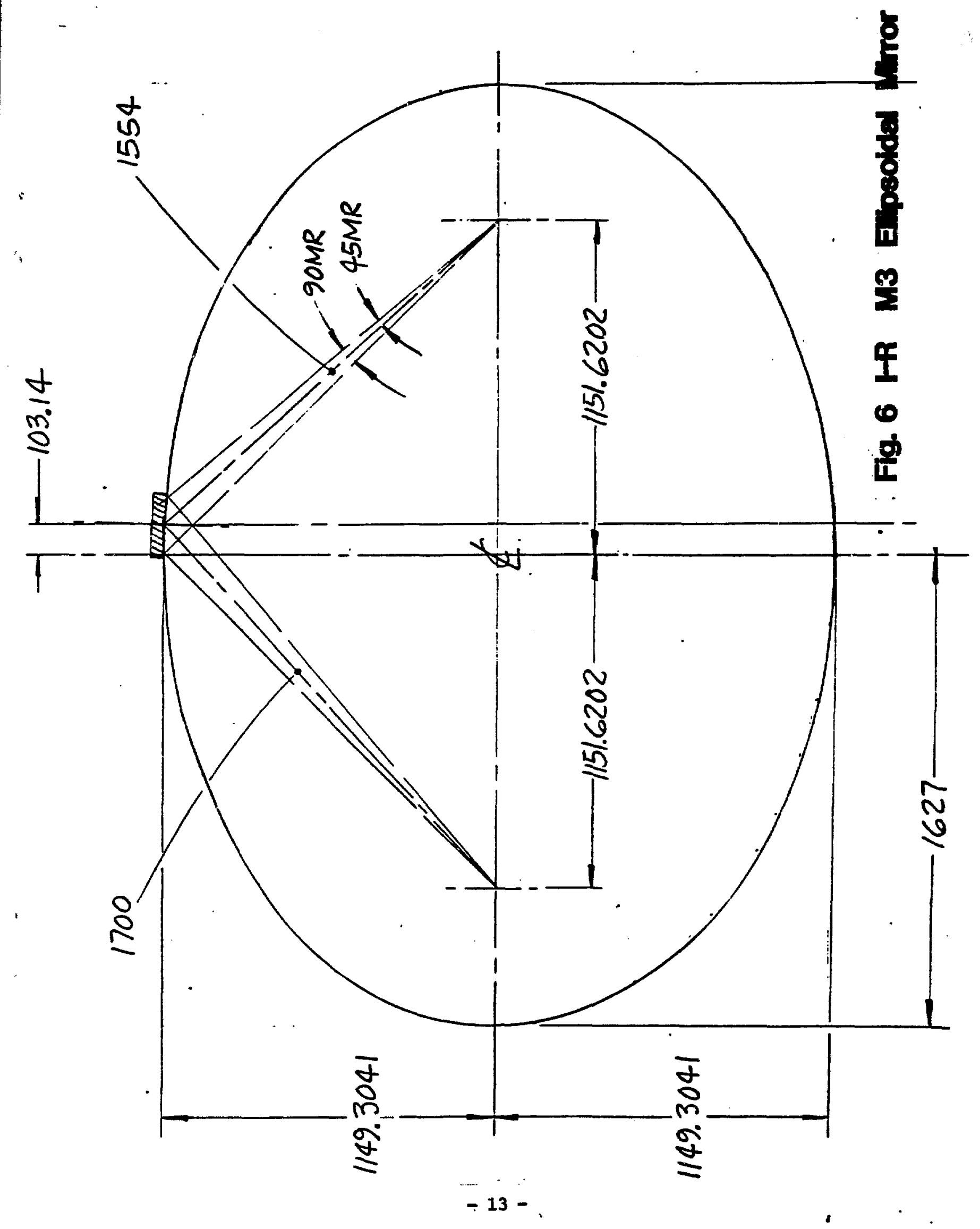

